$\S=-1$

\title{
Determination Parameters of a Hybridvehicle in Its Life Cycle
}

\author{
Mykyta Volodarets $^{1}$, Olha Kletska ${ }^{1 *}$, Viktoriia Hatchenko ${ }^{1}$, Dmitriy Shuleshko $^{1}$, Oleg Kosariev $^{1}$ \\ ${ }^{1}$ Ukrainian State University of Railway Transport \\ *Corresponding author E-mail: gurao@ukr.net
}

\begin{abstract}
This work considered methods of selection of power plant and energy storage of hybrid vehicle. An analysis has been performed and its shortcomings are indicated. A generalized scheme to define optimal technical and economic indexes of hybrid vehicle is drawn up and adapted for shunting locomotive. A model was created on its base with appropriate restrictions, which takes into account the shortcomings of existing models.

Parameters of different types of hybrid locomotives based on diesel locomotives series ChME3 were defined, depending on type of operation. Comparative traction characteristics of shunting locomotive series $\mathrm{ChMe} 3$ and diesel locomotive with hybrid transmission on the its base were built. Relevant calculations were fulfilled using these characteristics.
\end{abstract}

Keywords: indicators, hybrid transmission, locomotive, rolling stock, technical and economic parameters

\section{Introduction}

Technical basis and technological level of organization of transportation in many ways does not meet the needs of the society and European quality standards for transport services. The problem is complicated by the catastrophic lack of finances for the renovation of the traction rolling stock (TRS) that has been in operation for 25-30 years. Most locomotives in operation require 40-60\% higher maintenance and repair costs compared to modern foreign models. The measures which were taken to stabilize the railway complex failed to stop the critical deterioration of the basic funds of the Ukrainian railways and, most importantly, of rolling stock, which increased from $38 \%$ to $80 \%$ in the period since 1992 , as well as the active part - up to $85 \%$ [1]. From the existing fleet of locomotives, the service life, which was designated by the producing plants, $89.3 \%$ is used by electric locomotives, and $99.3 \%$ used by diesel locomotives.

Therefore, it is needed to upgrade the TRS of "Ukrzaliznytsya". It can be done in the following ways: by purchasing a new rolling stock or modernize an existing one with an extension of its lifetime up to 15-20 years [2,3]. Modernization is the most effective method to extend the service life of locomotives, especially in the face of a lack of finance and a high cost of a new locomotive park. One of the directions of increasing the efficiency of locomotive force is to solve issues that are related to the choice of types and characteristics of locomotives. These issues have always been reflected in research by scientists and specialists in rail transport and are very relevant, especially now.

One of the stages of solving this problem is the substantiation of parameters of perspective diesel locomotives, including those on which the hybrid drive is used. Therefore, the solution of these issues on the basis of modern theoretical developments allows us to qualify the work as actual, aimed at solving an important scientific and applied task of improving the methods and models for determining the tech-economic indicators of hybrid locomotives.

\section{The Main Content of the Work}

The main target state of diesel generator sets is a state that corresponds to the traction mode of the train with a power close to the nominal. The analysis of decoding BIS-R showed that the actual fuel consumption is usually higher than the cost specified in the technical certificate of the locomotive. This is primarily because to the long idle time of the locomotive, the frequent change in the position of the controller of the driver, the work on low positions of controller etc. When performing maneuvers, the locomotive for the most part operates in transient modes, with $50-60 \%$ of the time it operates in idle mode, $45-70 \%$ at low loads and only $2-5 \%$ at nominal loads [4].

One of the ways to increase the efficiency of shunting diesel locomotive operation $(\mathrm{ShD})$ is to replace an existing DGS with a lower power unit with an energy storage device (SD). As a SD may be used, batteries, accumulators, high capacity capacitors, and gyroscopes [5].

When modernizing a locomotive with a hybrid transmission its work on medium loads will be provided by the work of a lowpower engine; at idle speed and low load, a low-power engine will replenish the power reserve in SD and operate the locomotive; At high loads, the locomotive's work will be carried out at the expense of SD energy and due to the work of a low-power engine. In addition to the economic side, the reduction of fuel consumption, this modernization of locomotive will significantly improve the environmental performance of the locomotive [6].

A hybrid transmission on the railroad is being introduced around the world. However, all ShL operating in Ukraine have a transmission without SD. [3]

Many scientific studies are devoted to the definition and substantiation of the main indicators of locomotives. The main methods for selecting the parameters of the power unit and SD are shown in Figure 1 . 


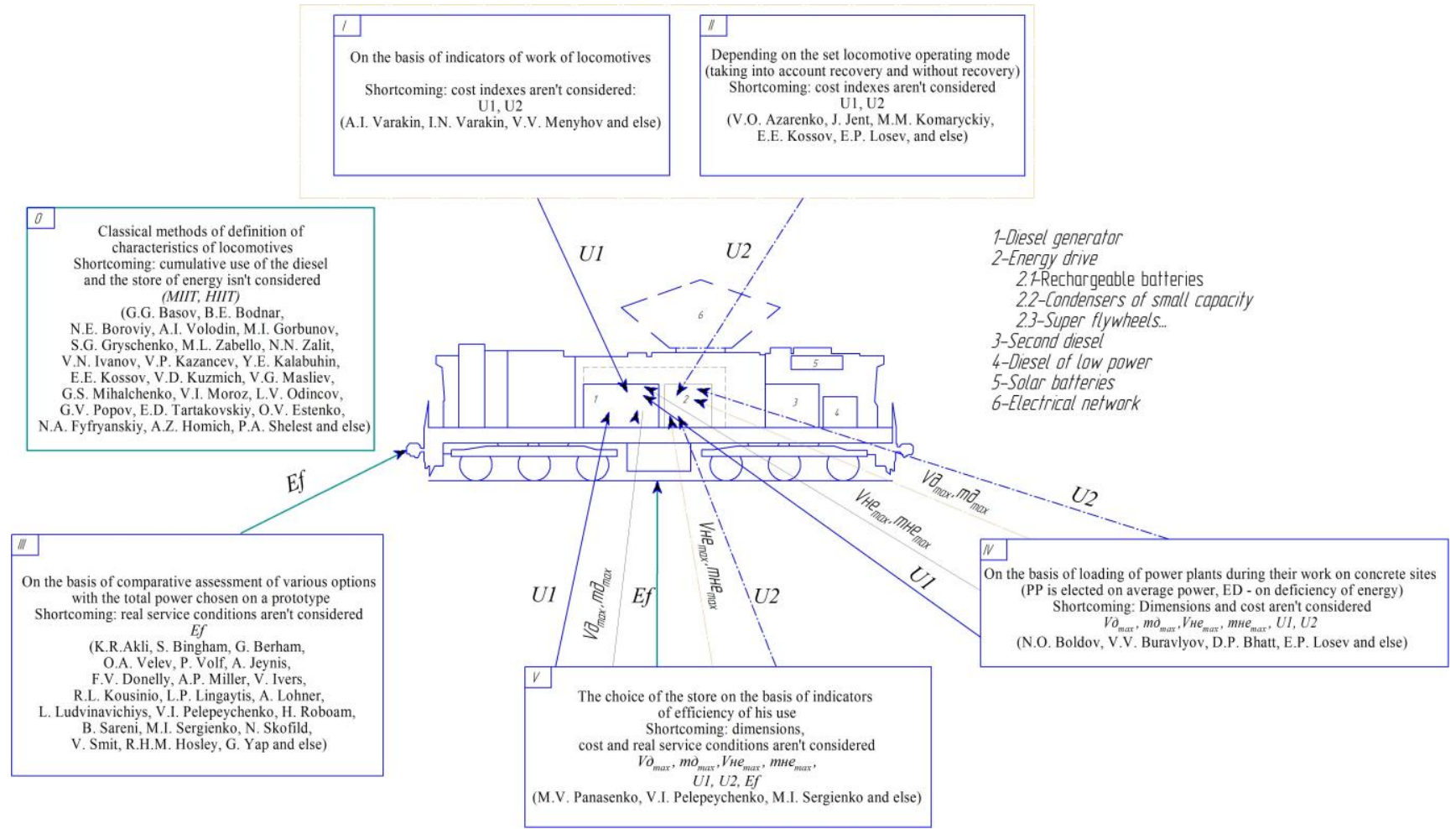

Fig. 1: Methods for selecting the power plant and energy storage parameters

As a result of the analysis of the scientists' work, the methods of selecting the parameters of the power plant and SD were divided into five categories: methods based on the average performance of locomotives; methods on the basis of comparative estimation of different variants with the total power chosen by the prototype choice depending on the given mode of operation of the locomotive (taking into account recovery and without recuperation); methods based on the loading of power plants, at their work in specific areas (PP is selected for average power, SD - for lack of energy); methods in which the choice is NOT made on the basis of performance indicators of its use.

In terms of methods and models, different scientists from different countries have been conducting research for many years to determine the tech-economic parameters of rolling stock. Some of them are suitable for hybrid locomotives, but they have a number of disadvantages. These methods don't take into account either cost figures, or actual operating conditions, or the size and performance of a mass of energy saving and power plant, or a set of parameters. Therefore, there is a scientific problem of development the methods and models for determining the parameters of the hybrid transmission ShD for its operation on the Ukrainian railways, taking into account these shortcomings. To solve the problem of determining the tech-economic parameters of hybrid locomotives, it's necessary to use a complex approach, which must interconnect the technical parameters of the engine, performance indicators and cost indicators.

In work [7], a method for calculating the parameters of a hybrid ShL was proposed. But it does not take into account the costs of maintenance and repair of the vehicle.

Therefore, we propose the following optimization model for determining the rational tech-economic parameters of hybrid ShL, which is a model of nonlinear programming. In an implicit way, its target function has the form, UAH,

$$
\begin{gathered}
\text { Uzag }(\text { Neng }, \text { Ene })=f(U 0, U 1(\text { Neng }), U 2(\text { Ene }), \\
U 3(\text { Neng, Ene }), U 4(\text { Neng, Ene }), k 3 m, k 8, k z) \rightarrow \min ,
\end{gathered}
$$

where $U O$ - cost of the basic DGS, UAH;

Ul(Neng) - cost of DGS depending on its power, UAH;

$\mathrm{U} 2$ (Ene) - cost of SD, UAH;

U3(Neng, Ene) - reduction of expenses for diesel fuel after modernization, UAH;

U4(Neng, Ene) - reduction of maintenance and repair costs after modernization, UAH;

$k з M-$ number of working changes per day;

$k b$ - number of days of using a locomotive for a year, days;

$k z$ - load factor of the locomotive during the day.

Taking into account the constraints imposed on SD and DGS, the optimal values of the power of the last Nopt, $\mathrm{kW}$, and the energy intensity of SD Eopt, MJ are provided, provided that the total costs associated with the upgrade of Uzag, are minimized, UAH

$$
\begin{gathered}
\operatorname{Uzag}_{j}(\text { Neng }, \text { Ene })=U 1_{j}\left(\text { Neng }_{j}\right)+U 2_{j}\left(\text { Ene }_{j}\right)- \\
-U 0-U 3_{j}\left(\text { Neng }_{j}, \text { Ene }_{j}\right) \cdot k 3 \mu \cdot k b \cdot k z \cdot r 0- \\
-U 4_{j}\left(\text { Neng }_{j}, \text { Ene }_{j}\right) \rightarrow \min
\end{gathered}
$$

where $\mathrm{r} 0$ - payback period from the introduction of the hybrid drive, years.

According to the developed scheme for determining the optimal technical and economic performance of a hybrid MT (Figure 2), it is first necessary to determine the initial parameters of the model. 


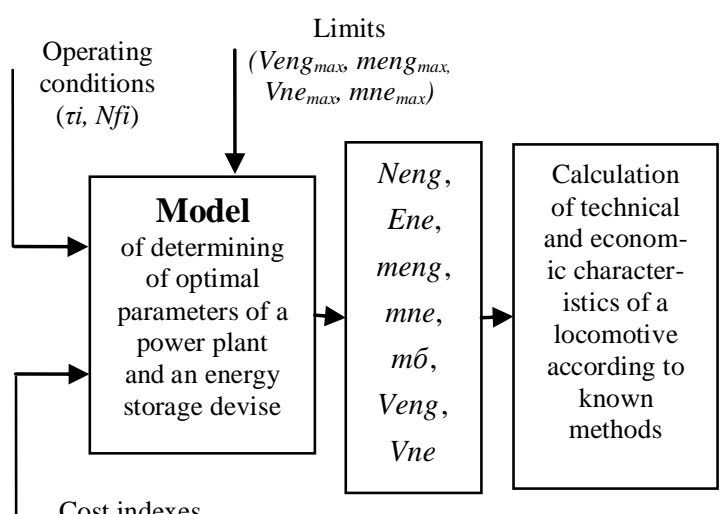

Cost indexes

and their TOR

(Ueng, Une,

$U_{\text {eng }}^{\text {mop }}, U_{n e}{ }^{\text {mop }}$

Fig. 2: Generalized scheme for determining the optimal technical and economic performance of a hybrid shunting diesel locomotive:

$\tau i$ - ShL operating time on the i-th mode, $s$; Nfi - power of the i-th operating mode ShL, kW; Ueng - cost of DGS, UAH; Une - cost of SD, UAH $\mathrm{U}_{\text {eng }}{ }^{\text {Top }}, \mathrm{U}_{\mathrm{ne}}{ }^{\text {то }}$ - cost indicators of maintenance and repair, respectively,

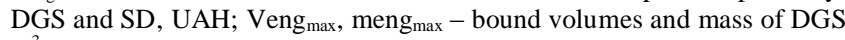
$\mathrm{m}^{3} ; \mathrm{Vne}_{\max }, \mathrm{mne}_{\max }-$ respectively, the limiting volume and mass SD, $\mathrm{kg}$, Neng - power of DGS, kW; Ene - capacity of SD, MJ; meng - weight of DGS, kg; mne - weight of SD, kg; mб - ballast weight, kg; Veng - volume of DGS, $\mathrm{m}^{3}$; Vne - volume of SD, $\mathrm{m}^{3}$

Then, according to the results of calculating the rational parameters of DGS and SD according to known methods [8-11], the techeconomic characteristics of ShL are determined. To do this, you need to set the function of the DGS cost of its power U1 (Neng) and the SD value of their power consumption U2 (Ene). In determining the value of DGS, the dependence of the price on it, depending on its long-term power, was obtained by approximating a number of discrete prices in dealer network for DGS produced by leading manufactures.

In explicit form, the target function of the model will look like, $\mathrm{UAH}$,

$$
\begin{gathered}
\operatorname{Uzag}_{j}(\text { Neng, Ene })=A \cdot\left(\text { Neng }_{j}\right)^{2}+B \cdot N e n g_{j}+C+ \\
+u 2 \cdot \text { Ene }_{j}-U 0-\left[\sum_{i=1}^{n}\left(N f_{i} \cdot g e 0 \cdot \frac{\Delta \tau}{3600}\right)-\sum_{i=1}^{n} G_{i, j}\right] \cdot \mathrm{ct}- \\
- \text { Cб } \cdot\left(1-k\left(N e n g_{j}\right)\right) \rightarrow \min .
\end{gathered}
$$

The limits imposed on the model are reduced to the system of inequalities

$$
\left\{\begin{array}{l}
m_{n e}(\text { Ene })+m_{\text {eng }}(N e n g) \leq m_{\mathrm{lim}} \\
V_{n e}(\text { Ene })+V_{\text {eng }}(N e n g) \leq V_{\text {lim }} \\
N f_{\min } \leq N f_{i} \leq N f_{\max } \\
N e n g_{\min } \leq N e n g_{j} \leq N f_{\max } \\
0 \leq \text { Ene } \leq m_{\max } \\
0 \leq \text { Ene }_{\text {m }}, v_{\max } \\
1 \leq i \leq n-1 \\
1 \leq j \leq N \text { steep } \\
0<k \leq 1
\end{array}\right.
$$

For the locomotive CHME3 formula (3) will take the following form, MJ,

$$
\begin{gathered}
\text { Uzag }_{j}(\text { Neng })=A \cdot\left(\text { Neng }_{j}\right)^{2}+B \cdot \text { Neng }_{j}+C+ \\
+u 2 \cdot\left(D \cdot\left(\frac{1}{\text { Neng }}\right)^{3}-E \cdot\left(\frac{1}{\text { Neng }}\right)^{2}+F \cdot\left(\frac{1}{\text { Neng }}\right)-G\right)-U 0- \\
-\left[\sum_{i=1}^{n}\left(N f_{i} \cdot g e 0 \cdot \frac{\Delta \tau}{3600}\right)-\sum_{i=1}^{n} G_{i, j}\right] \cdot \mathrm{ct}+C \sigma \cdot\left(H \cdot \text { Neng }_{j}+K-1\right) \rightarrow \mathrm{min},
\end{gathered}
$$

where A, B, C, D, E, F, G, H, K - are coefficients characterizing the type of selected DGS, type of operation, operating conditions and system of maintenance and repair of the locomotive.

Function (5) is a composite function, which includes functions that are continuous on a certain interval and a discrete function. Therefore, in an analytical form, it is not possible to obtain the optimal value of Neng power. It is not rational and approximate deterministic function dependence $\mathrm{G}$ (Neng), because it does not provide a simple universal formula for future calculations for fuel consumption considerably depending on the type of work, areas of operation, type and parameters are not hybrid locomotive that to obtain the required level the accuracy of the approximation requires the introduction of a large number of additional parameters and too complicates the function. Therefore, in order to solve the problem of nonlinear programming, a method of full-fledging was used as the simplest and one that gives fairly accurate results of calculations. Its main disadvantage is that it requires copying a large number of combinations, which takes a long time to get the solution. Therefore, the objective function $\operatorname{Uzag}_{j}(\mathrm{Neng})$ was simplified and reduced to one independent variable, subject to the limitations imposed on it, greatly reduce the number of combinations of length and sorting algorithms.

The cost and mass-dimensional indicators of DGS and SD for hybrid ShL, which operate in different operating modes, were calculated. Considered two types of hybrid drive: 1) the main source of energy DGS, and auxiliary SD;2) the main source of SD energy, and auxiliary DGS. It is revealed that the second type of hybrid drive is less effective on cost indicators, and in case of exit work, it also does not satisfy the mass-dimensional restriction of ShL. The results of calculating the parameters of both variants of hybrid locomotives on the basis of the locomotive of the ChME3 series, depending on the type of work performed, are given in Table 1.

Table 1: Parameters of hybrid locomotives on the basis of ChME3 series locomotive depending on the type of work performed.

\begin{tabular}{|c|c|c|c|c|c|c|}
\hline Parameter & \multicolumn{2}{|c|}{ Type of locomotive depending on the work performed } \\
\hline $\begin{array}{c}\text { Operation } \\
\text { type }\end{array}$ & \multicolumn{2}{|c|}{ Shunting } & 3 & \multicolumn{2}{|c|}{ Uphill work } & \multicolumn{2}{|c|}{ Removal work } \\
\hline $\begin{array}{c}\text { Type of hybrid } \\
\text { drive (main } \\
\text { power source } \\
\text { additional) }\end{array}$ & $\begin{array}{c}\text { DGS } \\
+\end{array}$ & $\begin{array}{c}\text { SD } \\
+ \\
\text { SDS }\end{array}$ & $\begin{array}{c}\text { DGS } \\
+ \\
\text { SD }\end{array}$ & $\begin{array}{c}\text { SD } \\
+\end{array}$ & $\begin{array}{c}\text { DGS } \\
+ \\
\text { DGS }\end{array}$ & $\begin{array}{c}\text { SD } \\
+ \\
\text { DGS }\end{array}$ \\
\hline $\begin{array}{c}\text { DGS power, kW } \\
\text { Energy in- } \\
\text { tensity of } \\
\text { SD, MJ }\end{array}$ & 150 & 50 & 200 & 80 & 530 & 100 \\
\hline $\begin{array}{c}\text { DGS weight, } \\
\text { t }\end{array}$ & 2.052 & 0.96 & 2.252 & 1.26 & 3.987 & 1.417 \\
\hline SD weight, t & 0.42 & 7.77 & 1.05 & 11.76 & 1.05 & 27,3 \\
\hline Ballast, $\mathrm{n}$ & 15.578 & 9.32 & 14.748 & 5.03 & 13.013 & -10.667 \\
\hline $\begin{array}{c}\text { Cost of } \\
\text { DGS, } \\
\text { thousand } \\
\text { UAH }\end{array}$ & 298.13 & 181.8 & 364.5 & 214.4 & 940.63 & 237.22 \\
\hline $\begin{array}{c}\text { Cost of SD, } \\
\text { thousand } \\
\text { UAH }\end{array}$ & 400 & 7400 & 1000 & 11200 & 1000 & 26000 \\
\hline $\begin{array}{c}\text { Cost of } \\
\text { DGS+SD, } \\
\text { thousand } \\
\text { UAH }\end{array}$ & 698.13 & 7582 & 1365 & 11414 & 1940.6 & 26237 \\
\hline
\end{tabular}


With the help of traction calculations, a comparative analysis of two locomotives of the base CHME 3 and a hybrid on its base (the first variant of hybridization for the export work) was performed. The calculations were carried out using the Mathcad software system with a 500-tonne train for the exit work on the StakhanovPopasna profile.

To perform traction calculations, locomotive parameters were used based on the results of previous calculations for the exit work on the first type of hybrid drive locomotive.

The traction characteristics of the ChME3 diesel locomotive and the hybrid on its base, for which it was obtained with the help of the developed software complex, is shown in Figure 3.

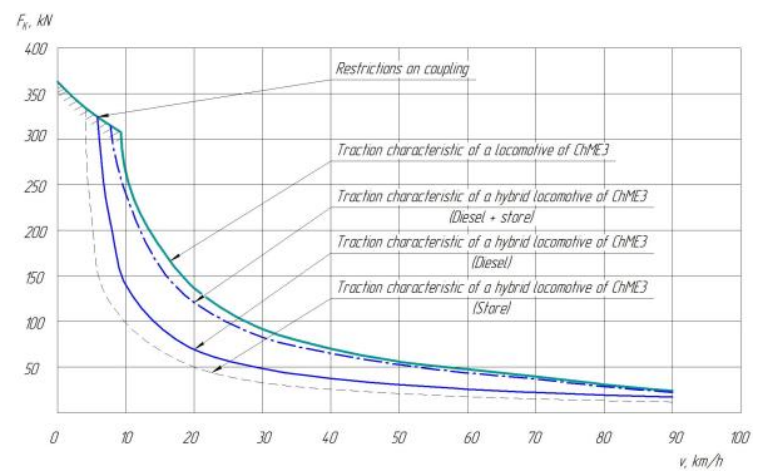

Fig. 3: The traction characteristics of the shunting diesel locomotive of the ChME3 series and the hybrid on its base.

The traction characteristics of the hybrid diesel locomotive on the basis of ChME3 are given for three modes of its operation, namely:

- for mode when working only SD;

- for mode when working only DGS;

- for mode when Sd and DGS working together.

These features of the hybrid SHL work and were taken into account when conducting traction calculations.

The results of traction calculations for ChME3 locomotives are shown in Figure 4.

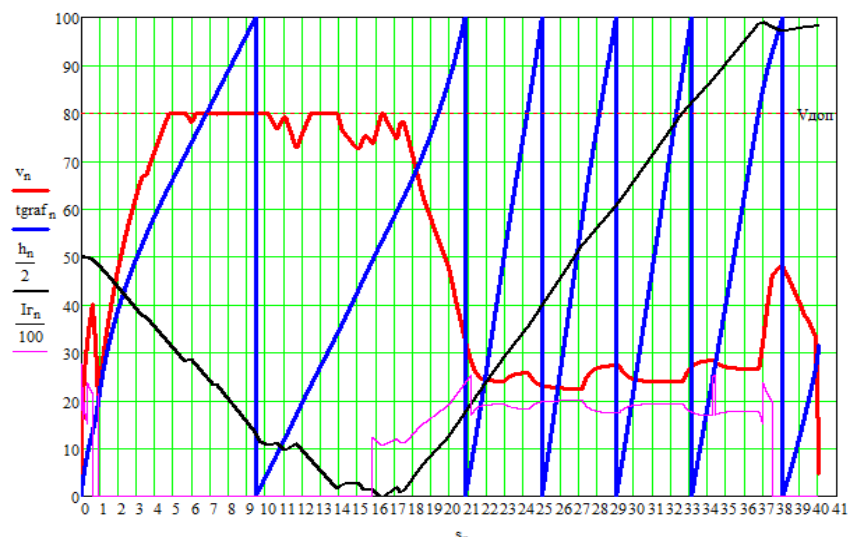

Fig. 4: Traction calculations of diesel locomotive of ChME3 series, which moves with a train of mass $500 t$ by profile Stakhanov-Popasna: $v_{n}-$ speed curve, $\mathrm{km} / \mathrm{h} ;$ tgraf $_{\mathrm{n}}$ - curve of time running, $\min ; \mathrm{h}_{\mathrm{n}} / 2$ - profile of the train motion section, $\Gamma_{\Gamma_{n}} / 100-$ current curve, A, $s_{n}-$ path of the train, $\mathrm{km}$.

The limits of motion on this profile are $80 \mathrm{~km} / \mathrm{h}$. In traction mode, the train begins to move at a speed of $40 \mathrm{~km} / \mathrm{h}$. Then the brakes are tested before a long descent, reducing the speed to $20 \mathrm{~km} / \mathrm{h}$ and continuing to increase speeds up to $80 \mathrm{~km} / \mathrm{h}$, moving in working mode. It also takes into account the fact that the train reaches the station on the arrows of the station at a speed of less than 50 $\mathrm{km} / \mathrm{h}$. Figure 4 shows the speed curve, train time curve, current curve, as well as the profile of the area on which the train moves. In Figure 5 for one section and trains weighing $500 \mathrm{t}$, traction calculations for the SHL CHME3 hybrid diesel locomotive, the parameters of which were calculated above, are presented.

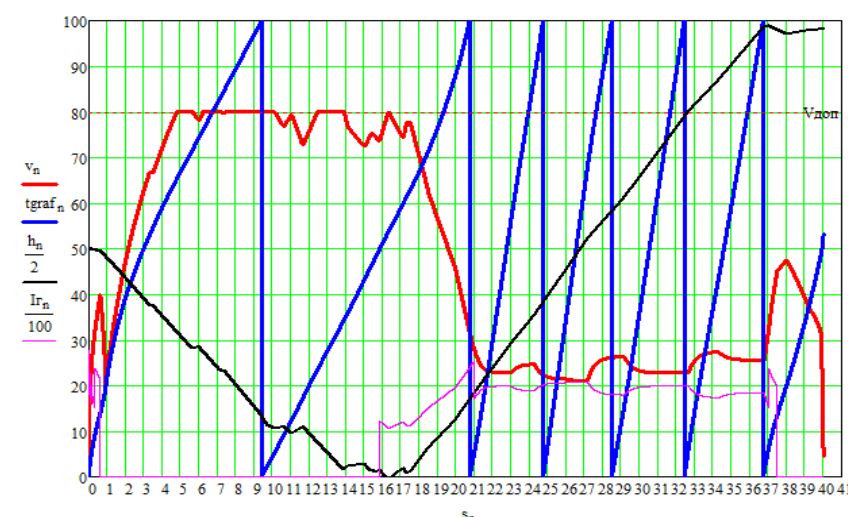

Fig. 5: Traction calculations of the hybrid diesel locomotive on the basis of ChME3, which moves with a train of mass 500t by profile StakhanovPopasna: $\mathrm{v}_{\mathrm{n}}-$ speed curve, $\mathrm{km} / \mathrm{h}$; tgraf $\mathrm{f}_{\mathrm{n}}$ - curve of time running, $\min$.; $\mathrm{h}_{\mathrm{n}} / 2$ - profile of the train motion section, $\mathrm{I}_{\mathrm{n}} / 100$ - current curve, $\mathrm{A} ; \mathrm{s}_{\mathrm{n}}$ - path of the train, $\mathrm{km}$.

The mode of movement was chosen the same as for the base locomotive. A fragment of the traction calculation program is given in Addition B.

It turns out that for almost the same time, the fuel consumption of the hybrid $\mathrm{ShL}$ is $30 \%$ less than the base engine locomotive of the CHME 3 series, and the efficiency of the trips with the modernized locomotive has increased by $7 \%$.

The efficiency of the hybrid ShL in comparison with the base locomotive was calculated according to the model set out in [12, 13], which in general looks

$K e f_{s}=\frac{\frac{\sum_{i=1}^{i=q r} k_{n s} \varphi(i)}{\sum_{i=1}^{i=q r} \varphi(i)}+\frac{L L C_{T \sigma s}}{L L C_{T e s}}+\frac{\sum_{z=1}^{n} A_{z}^{\prime} m_{\sigma z s}}{\sum_{z=1}^{n} A_{z}^{\prime} m_{z z s}}}{3}$

Taking into account the above calculations, as well as the declared ecological indicators of diesels for maneuvering work, the coefficient of efficiency of the use of hybrid MT was calculated. It turned out to be equal to $\mathrm{Kef}_{1}=1,9$ for maneuvering work, for work on a hill $-\mathrm{Kef}_{2}=2,2$, for the exit work $-\mathrm{Kef}_{3}=2,9$. Therefore, the proposed version of the modernization of the ShL series ChME3 hybrid power transmission is appropriate for all considered variants of its operational work.

\section{Conclusions}

1. The analysis of the existing fleet of locomotives has been carried out, which showed that ShL have been in operation for $90 \%$ of their service life, their operation is characterized by a sharply variable mode in which DGS works most of the time in uneconomical mode, which emphasizes the practical relevance of this issue. It is proved that the creation of a hybrid locomotive based on ShL ChME3 is an expedient solution.

2. The analysis of the works of scientists shows that in order to solve the problem of determining the technical and economic indicators of hybrid locomotives, a comprehensive approach is needed that should interconnect the technical parameters of the locomotive, performance indicators and cost indicators. In order to justify the choice of technical and economic indicators of hybrid locomotives, a certain approach based on mathematical modeling is chosen and it is possible to substantiate the choice of the main technical and economic indicators of the locomotive at the lowest cost of the life cycle under certain operating conditions.

3. An optimization mathematical model for determining the parameters of a power plant and SD, taking into account engine operating conditions and its mass-dimensional constraints, has been developed. 
4. Based on the developed models, an algorithm of the program and a program for calculating the required energy intensity SD and the power of the ShL power unit with a hybrid transmission using the Mathcad software package is compiled. Using the program, DGS and SD parameters for the ChME3 hybrid locomotive for certain types of operation and operating conditions were determined. The parameters of several variants of hybrid diesel locomotives depending on the type of exploitation works are calculated.

5. Traction calculations using the software complex Mathcad for the Stakhanov-Popasna profile with a 500-tonne train were carried out for the exit work according to the parameters of the locomotive selected according to the calculation results. The driving modes of both locomotives were selected so that the traffic time, as well as the run and braking were approximately the same. The traction characteristic of the hybrid locomotive based on the ShL series ChME3 was obtained using the developed models. It was found that as a result of replacing the base ShL ChME3 series with a hybrid locomotive constructed on its base, for the considered section and corresponding mass of the train, the total fuel consumption will be reduced by $30 \%$, and the efficiency of the trip will increase by $7 \%$.

6. The efficiency factor from the introduction of the hybrid ShL instead of the locomotive of the ChME3 series, which was equal to the maneuvering work, was calculated. $K_{\mathrm{ef}(\mathrm{sh} .)}=1,9$, operation on the hill $\mathrm{K}_{\mathrm{ef}(\mathrm{sh} .)}=2,2$, removal work $\mathrm{K}_{\mathrm{ef}(\mathrm{sh} .)}=2,9$, which fully confirms the effectiveness of the implementation of this type of MT instead of the locomotive series ChME3 for all considered variants of its operational work.

\section{References}

[1] Sergiyenko, N.I. Resheniye problem podvizhnogo sostava zheleznykh dorog Ukrainy cherez vzaimodeystviye gosudarstven-nogo i chastnogo sektorov ekonomiki [Tekst] // Lokomotiv-inform. 2010. - №6. - S.40-46.

[2] Lashko, A.D. Osnovny`e napravleniia obnovleniia tiagovogo podvizhnogo sostava Ukrainy`v 2006-2010 gg. [Tekst] / A.D. Lashko, V.N. Samsonkin, A.M. Goncharov, A.V. Konovalov // Lokomotiv-inform. - 2006. -№6. - S.8-12.

[3] Falendy`sh, A.P. Ispol`zovanie gibridny`kh peredach na manevrovy`kh teplovozakh [Tekst] / A.P. Falendy`sh, N.V. Volodaretc // Lokomotiv-inform. - 2010. - Dekabr`. - S. 4-7.

[4] Molchanov, A.I. Avtomatizirovannaia sistema ucheta, kon-trolia i analiza rashoda topliva manevrovy`mi teplovozami [Tekst] / A.I. Molchanov, I.L. Povarkov, L.A. Muginshtei`n, K.M. Popov // Vestneyk VNIIZHT. - 2004. - №2. - S. 36-42.

[5] Gulia, N.V. Nakopiteli e`nergii [Tekst] / N.V. Gulia. - M.: Nauka 1980. - S.137-138

[6] Malozemov, N.A. Teplovozoremontny`e predpriiatiia. Organizatciia, planirovanie i upravlenie [Tekst] / N.A. Maloze-mov, A.I Iunihin, M.P. Kaplunov. - M.: Transport, 1979. - 264 s.

[7] Anatoliy Falendysh, Pavel Kharlamov, Olga Kletska, Nikita Volodarets, Calculation of the Parameters of Hybrid Shunting Locomotive, Transportation Research Procedia, Volume 14, 2016, Pages 665-671, ISSN 2352-1465, http://dx.doi.org/10.1016/j.trpro.2016.05.325.

[8] The impact of the type of operation on the parameters of a shuning diesel locomotive with hybrid power plant / Anatoliy Falendysh, Mykyta Volodarets, Olha Kletska, Viktoriia Hatchenko // MATEC Web Conferences 133.03003 (2017) BulTrans-2017. (http://creativecommons.org/licenses/by/4.0/). DOI $10.1051 /$ matecconf/201713303003.

[9] Kossov, E.E. Vy`bor harakteristik magistral`ny`kh i manev-rovy`kh teplovozov [Tekst] / E.E. Kossov, V.A. Starovoi`t // Povy`shenie toplivnoi ekonomichnosti teplovozov: trudy VNIIZHT. - M. Transport, 1991.- $238 \mathrm{p}$.

[10] Mihal 'chenko, G.S. Teoriia i konstruktciia lokomotivov: Uchebnik dlia vuzov zh.-d. transporta [Tekst] / G.S. Mihal'chenko, V.N. Kashnikov, B.C. Kossov, V.A. Simonov.- M.: Marshrut, 2006. $584 \mathrm{p}$.

[11] Strekopy`tov, V.V. E`lektricheskie peredachi lokomoti-vov: Uchebnik dlia vuzov zh.-d. transporta [Tekst] / V.V. Strekopy`tov, A.V. Grishchenko, V.A. Kruchek. M.: Marshrut, 2003. 310 p.
[12] Voron`ko, V.A. Obosnovanie vy`bora parametrov manevrovykh i promyshlennykh teplovozov $\mathrm{s}$ uchetom uslovii ekspluatatcii [Tekst]: dis. ... k. t. n. spetc. 05.22.07 - Podvizhnoi` sostav zhedezny`kh dorog, tiaga poezdov / V.A. Voron`ko. M.: MGUPS, 2005. $148 \mathrm{p}$.

[13] Falendysh, A. Determination of implementation efficiency of hybrid shunting diesel locomotive, taking into account the type of field operation / A. Falendysh, M. Volodarets, M. Bragin, Y. Biletskyi // TEKA. Commission of motorization and energetics in agriculture. Lublin. - 2015. - Vol. 15. - No 3. - P. 15-20.

[14] Volodarets, M. Assessment of vehicle effective modernization taking into account the life cycle cost, technical and environmental parameters/ M. Volodarets // Automobile transport: collection of scient. works / Ministry of education and science of Ukraine, KhNAHU; [editorial board: A.N. Turenko (editor-in-chief.) et al.] Kharkov, 2016. - Iss. 39. - P. 90-94. 